\title{
Analisis Aliran Beban Pada Sistem Tenaga Listrik di PT XYZ
}

\author{
Pujianto, Astrie Kusuma Dewi, Anton Mulyono
}

Politeknik Energi dan Mineral Akamigas (PEM Akamigas), Cepu

\section{INFORMASI NASKAH}

Diterima: 20 Januari 2021 Direvisi: 29 Januari 2021

Disetujui: 20 Februari 2021 Terbit: 30 Juni 2021

Email korespondensi: pujianto@esdm.go.id

Laman daring:

https://doi.org/10.37525/

$\mathrm{mz} / 2021-1 / 262$

\begin{abstract}
ABSTRAK
Dalam sistem tenaga listrik, studi aliran beban sangat diperlukan dalam perhitungan maupun simulasi sebagai acuan dalam perbaikan sistem agar lebih optimal. Analisis aliran beban dapat dilakukan dalam berbagai metode, antara lain dengan menggunakan perangkat lunak, salah satunya ETAP Power Station yang mendukung dalam hal studi aliran beban. Untuk proses pembangkitan listrik di PT.XYZ ditemukan beberapa pengaturan yang kurang tepat sehingga beberapa titik ditemukan adanya over voltage, under voltage, dan overload pada jaringan distribusi listrik. Selain itu, rencana pemindahan Generator D3512B2 untuk area X menjadi pembahasan utama, solusi yang diambil dengan penyambungan jalur $20 \mathrm{kV}$ dari PLN diharapkan dapat menyalurkan tanpa ada gangguan pada distribusi listrik seperti yang sudah disimulasikan. Berdasarkan perhitungan keekonomian diprediksi dapat menghemat biaya operasi sampai dengan $50 \%$ dan mendapatkan Pay Back Period dalam jangka waktu 78 hari.
\end{abstract}

Kata kunci: Studi aliran beban, software ETAP, sumber listrik PLN

\section{ABSTRACT}

In electric power systems, flow studios are needed in calculations so that they can be repaired in the system to be more optimal. Load flow analysis can be carried out in a variety of methods, including using software, one of which is ETAP Power Station which supports load flow studies. For the electricity generation process in XYZ found some settings that are not appropriate according to some points found there are more than voltage, under voltage, and excess in the electricity distribution network. In addition, the plan to move the D3512B2 Generator to the $X$ area is the main discussion, a solution taken with a $20 \mathrm{kV}$ line distributor from PLN which is expected to be able to channel 
without a connection to the approved electricity distribution. Based on economic calculations it is predicted to save operating costs up to $50 \%$ and get a repayment period within 78 days.

Keywords: Study of load flow, ETAP

software, PLN power source

\section{PENDAHULUAN}

Dalam proses lifting, processing hingga transfering minyak mentah (crude oil) sebagai hasil dari aktivitas produksi masih menggunakan peralatan dan unit operasi yang memerlukan energi listrik sebagai sumber tenaga penggeraknya. Tenaga listrik yang dihasilkan bersumber dari pusat pembangkit yang terdiri dari beberapa unit generator yang digerakkan oleh gas engine dan diesel engine. Salah satu pembangkit yang memiliki sistem kelistrikan yang cukup kompleks yaitu pembangkit yang terdapat di PT.XYZ yang memiliki 2 unit pembangkit Diesel Engine Generator (DEG) D-3512B dan 1 unit Gas Engine Generator (GEG) G-3412NA untuk memenuhi seluruh kebutuhan listrik baik pada fasilitas umum maupun fasilitas produksi. Dalam proses pembangkitan, seiring dengan bertambahnya peralatan maupun unit operasi produksi yang berpengaruh terhadap perubahan beban. Hal ini menyebabkan kondisi jaringan sistem tenaga listrik menjadi semakin kompleks dan rumit. Tanpa adanya pengelolaan yang baik, maka akan memperbesar rugi-rugi daya yang terjadi serta memperburuk profil tegangan. Oleh karena itu, perlu adanya dilakukan studi aliran beban terkait penambahan beban yang terjadi.

Dalam pengolahan data diperlukan perangkat lunak untuk menyelesaikan studi aliran beban, salah satunya software ETAP Power Station. Software ETAP Power Station merupakan software yang digunakan untuk simulasi jaringan listrik, salah satunya menyelesaikan studi aliran beban. Software ETAP juga telah diakui menjadi software berlisensi yang digunakan di seluruh wilayah kerja di Indonesia untuk keperluan simulasi suatu sistem distribusi tenaga listrik. Berdasarkan simulasi yang dilakukan pada software ETAP maka diketahui besarnya rugirugi daya dan kondisi profil tegangan pada sistem tenaga listrik.

Selain ketidaksediaan data dalam pembuatan studi aliran beban yang menjadi kendala utama, perihal rencana untuk pengembangan dengan pemasangan PLN 20 $\mathrm{kV}$ sebagai pengganti generator G3412NA menjadi aspek yang harus dikaji lebih lanjut. Oleh karena itu perlu adanya suatu simulasi aliran beban dan studi nilai keekonomian terkait rencana pengembangan yang akan diambil sehingga dapat diketahui sejak dini dampak yang akan timbul dari proses pengembangan tersebut.

\section{METODE PENELITIAN}

Dalampenulisanini, penulis menggunakan metodologi penulisan sebagai berikut :

2.1 Pengumpulan Data

Untuk lokasi pengumpulan data dilakukan di pusat pembangkit PT. XYZ, dimana untuk data yang dikumpulkan berupa basis data pembangkitan, jalur distribusi dan beban-beban terpasang.

\subsection{Permodelan dan Simulasi}

Dari data yag diperoleh dibuat suatu permodelan baik dengan software AutoCAD dan ETAP untuk kemudian diketahui profil beban, gangguan yang ditimbulkan, dan dampak terkait rencana pengembangan dengan pemasangan jalur PLN $20 \mathrm{kV}$.

\subsection{Analisis dan Evaluasi}

Setelah diketahui hasil dari simulasi maka penulis menganalisis penyebab gangguan dan metode untuk mengatasi gangguan tersebut, baik dengan cara pengaturan parameter pada peralatan listrik 
maupun dengan penambahan peralatan di lokasi tempat terjadinya gangguan. Selain itu dapat dianalisis terkait rencana pengembangan jalur PLN $20 \mathrm{kV}$ yang berdampak pada sistem kelistrikan yang ada.

2.4 Tinjauan Keekonomian

Dalam rencana pengembangan jalur PLN 20kV, selain ditinjau dari aspek kelistrikannya juga dapat ditinjau dari aspek ekonomi baik dari penghematan yang diperoleh maupun pay back period dari suatu rencana pengembangan yang dilakukan.

\section{HASIL PENELITIAN DAN PEMBAHA-} SAN

Dalam pembahasan penelitian ini penulis berfokus kepada permodelan sistem, simulasi data, analisis data, evaluasi data dan keekonomian. Adapun rincian pembahasan sebagai berikut :

\subsection{Permodelan Sistem Distribusi}

Permodelan sistem dilakukan dengan 2 tahapan yaitu tahap pertama dengan pembuatan Single Line Diagram (SLD) menggunakan software AutoCAD dengan tujuan agar memudahkan dalam proses pengarsipan dan berbagi data serta untuk menentukan jarak kabel dari gardu trafo menuju titik beban baik Stasiun Pengumpul maupun sumur produksi yang ditunjukan pada Gambar 1.

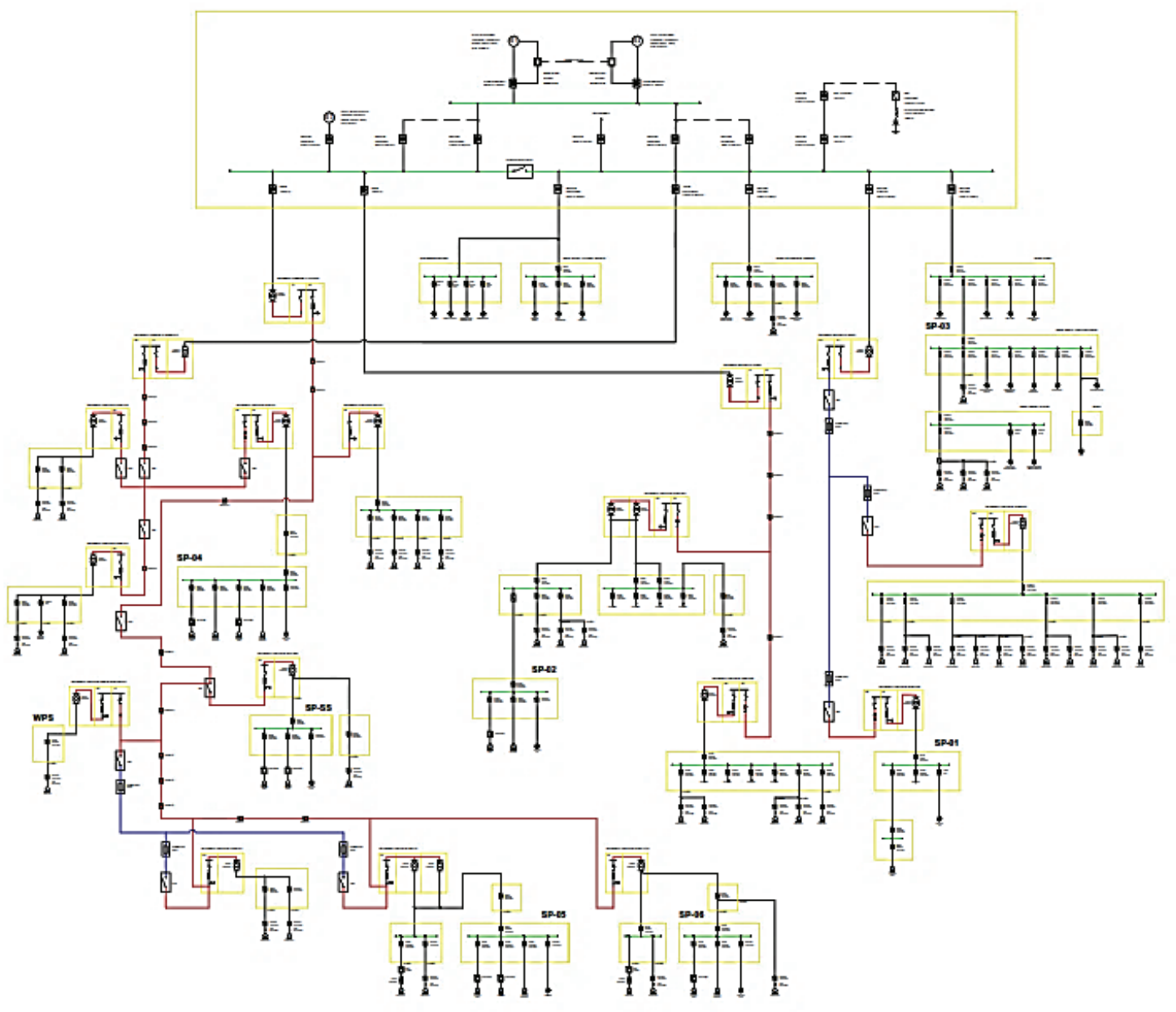

Gambar 1. Hasil Single Line Diagram (SLD) Pembangkit Tenaga Listrik 
Dilanjutkan dengan permodelan menggunakan software ETAP yang dalam pembuatannya menyertakan spesifikasi peralatan secara detail untuk kebutuhan simulasi, yang ditunjukan pada Gambar 2.

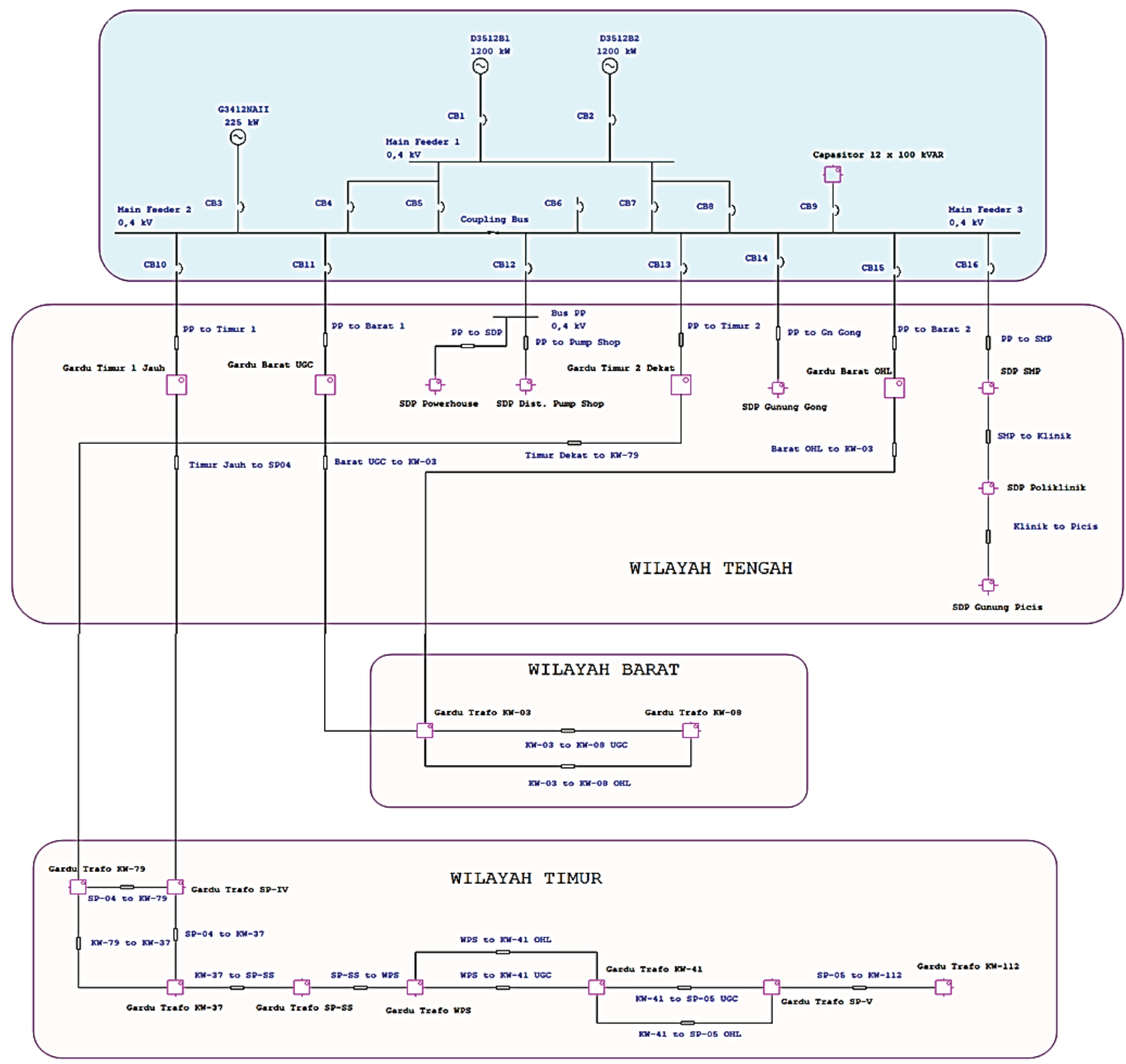

Gambar 2. Hasil Permodelan dengan Software ETAP untuk Pembangkit 
3.2 Simulasi dan Analisis Gangguan

Simulasi akan dilakukan secara bertahap untuk semua Stasiun Pengumpul secara bergantian yang kemudian akan dibuat daftar gangguan dan dianalisis untuk menentukan tindakan yang evaluasi. Untuk simulasi dilakukan di 6 SP antara lain SP-01, SP-02, SP-SS, SP-04, SP-05 dan SP-06. Dalam hasil simulasi, terdapat kondisi critical yang ditandai dengan komponen berwarna merah yang artinya perlu dilakukan evaluasi segera agar sistem tetap aman dan kondisi marginal yang ditandai dengan komponen berwarna ungu artinya masih dalam batas toleransi keadaan aman namun tetap evaluasi sehingga dapat dicegah sejak dini potensi terjadinya gangguan di kemudian hari.

Adapun hasil simulasi dan analisis yang sudah dilakukan sebagai berikut :

Tabel 1. Hasil Simulasi Gangguan

\begin{tabular}{|l|l|}
\hline $\begin{array}{c}\text { Tingkat } \\
\text { Gangguan }\end{array}$ & \multicolumn{1}{c|}{ Jenis Gangguan } \\
\hline Marginal & $\begin{array}{l}\text { 14 lokasi gangguan } \text { over } \\
\text { voltage, 2 lokasi ganggan } \\
\text { overload dan 7 gangguan } \\
\text { under voltage }\end{array}$ \\
\hline Critical & $\begin{array}{l}\text { 4 lokasi gangguan } \text { overload } \\
\text { pada trafo Gardu Distribusi }\end{array}$ \\
\hline
\end{tabular}

Adapun rincian hasil analisis gangguan critical sebagai berikut :

1. Untuk Trafo KW-03 2 (200 kVA) terindikasi overload dimana untuk pengaturan alert pada transformator sebesar $50 \%$, sedangkan beban operasi sebesar $110.3 \mathrm{kVA}$ yaitu $55.2 \%$ dari kapasitas trafo. Hal tersebut terjadi saat pompa transfer SP-01 dan SP-02 dioperasikan.

2. Untuk Trafo KW-03 3 (200 kVA) terindikasi overload dimana untuk pengaturan alert pada transformator sebesar $50 \%$, sedangkan beban operasi sebesar 110.3 kVA yaitu $55.2 \%$ dari kapasitas trafo. Hal tersebut terjadi saat pompa transfer SP-01 dan SP-02 dioperasikan.

3. Untuk Trafo KW-05 2 (200 kVA) terindikasi overload dimana untuk pengaturan alert pada transformator sebesar $50 \%$, sedangkan beban operasi sebesar $198.7 \mathrm{kVA}$ yaitu $99.35 \%$ dari kapasitas trafo. Hal tersebut terjadi saat pompa transfer SP dioperasikan.

4. Untuk Trafo Timur Jauh (1000 kVA) terindikasi overload dimana untuk pengaturan alert pada transformator sebesar 50\%, sedangkan beban operasi sebesar 519 kVA yaitu 51.9\% dari kapasitas trafo. Hal tersebut terjadi saat pompa transfer SP-SS dioperasikan.

Adapun rincian hasil analisis gangguan marginal sebagai berikut :

1. Untuk Bus Gudang Handak terindikasi over voltage, dimana rating tegangan operasi $380 \mathrm{~V}$ namun terukur $413 \mathrm{~V}$ atau $108.7 \%$ dari tegangan operasi.

2. Untuk Bus Kantor Desa terindikasi under voltage, dimana rating tegangan operasi $380 \mathrm{~V}$ namun terukur $361 \mathrm{~V}$ atau $94.9 \%$ dari tegangan operasi.

3. Untuk Bus KW-03 terindikasi over voltage, dimana rating tegangan operasi $380 \mathrm{~V}$ namun terukur $409 \mathrm{~V}$ atau $107.7 \%$ dari tegangan operasi.

4. Untuk Bus KW-06 terindikasi over voltage, dimana rating tegangan operasi $380 \mathrm{~V}$ namun terukur $408 \mathrm{~V}$ atau $107.3 \%$ dari tegangan operasi.

5. Untuk Bus KW-08 terindikasi over voltage, dimana rating tegangan operasi $380 \mathrm{~V}$ namun terukur $409 \mathrm{~V}$ atau $107.7 \%$ dari tegangan operasi.

6. Untuk Bus KW-13 terindikasi over 
voltage, dimana rating tegangan operasi $380 \mathrm{~V}$ namun terukur $406 \mathrm{~V}$ atau $106.8 \%$ dari tegangan operasi.

7. Untuk Bus KW-17 terindikasi over voltage, dimana rating tegangan operasi $380 \mathrm{~V}$ namun terukur $407 \mathrm{~V}$ atau $107.2 \%$ dari tegangan operasi.

8. Untuk Bus KW-22T terindikasi over voltage, dimana rating tegangan operasi $380 \mathrm{~V}$ namun terukur $405 \mathrm{~V}$ atau $106.5 \%$ dari tegangan operasi.

9. Untuk Bus KW-36 terindikasi over voltage, dimana rating tegangan operasi $380 \mathrm{~V}$ namun terukur $399 \mathrm{~V}$ atau $105 \%$ dari tegangan operasi.

10. Untuk Bus KW-36T terindikasi over voltage, dimana rating tegangan operasi $380 \mathrm{~V}$ namun terukur $399 \mathrm{~V}$ atau $105 \%$ dari tegangan operasi.

11. Untuk Bus KW-71 terindikasi under voltage, dimana rating tegangan operasi $380 \mathrm{~V}$ namun terukur $354 \mathrm{~V}$ atau $93.1 \%$ dari tegangan operasi.

12. Untuk Bus KW-77 terindikasi under voltage, dimana rating tegangan operasi $380 \mathrm{~V}$ namun terukur $359 \mathrm{~V}$ atau $94.4 \%$ dari tegangan operasi.

13. Untuk Bus KW-84 terindikasi under voltage, dimana rating tegangan operasi $380 \mathrm{~V}$ namun terukur $360 \mathrm{~V}$ atau $94.7 \%$ dari tegangan operasi.

14. Untuk Bus KWP-01 terindikasi over voltage, dimana rating tegangan operasi $380 \mathrm{~V}$ namun terukur $404 \mathrm{~V}$ atau $106.4 \%$ dari tegangan operasi.

15. Untuk Bus KWP-20 terindikasi under voltage, dimana rating tegangan operasi $380 \mathrm{~V}$ namun terukur $357 \mathrm{~V}$ atau $93.8 \%$ dari tegangan operasi.

16. Untuk Bus Picis terindikasi under voltage, dimana rating tegangan operasi 380V namun terukur $361 \mathrm{~V}$ atau $95 \%$ dari tegangan operasi.

17. Untuk Bus Sarana Umum terindikasi under voltage, dimana rating tegangan operasi $380 \mathrm{~V}$ namun terukur $361 \mathrm{~V}$ atau 95\% dari tegangan operasi.

18. Untuk Bus SP-01 terindikasi over voltage, dimana rating tegangan operasi $380 \mathrm{~V}$ namun terukur $413 \mathrm{~V}$ atau $108.6 \%$ dari tegangan operasi.

19. Untuk Bus SP-02 terindikasi over voltage, dimana rating tegangan operasi $380 \mathrm{~V}$ namun terukur $409 \mathrm{~V}$ atau $107.7 \%$ dari tegangan operasi.

20. Untuk Bus SP-04 04 terindikasi over voltage, dimana rating tegangan operasi $380 \mathrm{~V}$ namun terukur $416 \mathrm{~V}$ atau $109.5 \%$ dari tegangan operasi.

21. Untuk Bus SP-SS 03 terindikasi over voltage, dimana rating tegangan operasi $380 \mathrm{~V}$ namun terukur $412 \mathrm{~V}$ atau $108.2 \%$ dari tegangan operasi.

22. Untuk Trafo SP-05 1 (200 kVA) terindikasi mendekati batas overload dimana untuk pengaturan alert pada transformator sebesar $50 \%$, sedangkan beban operasi sebesar $97.9 \mathrm{kVA}$ yaitu $49 \%$ dari kapasitas trafo. Hal tersebut terjadi saat pompa transfer SP-01, SP02, SP-04 dan SP-06.

23. Untuk Trafo Timur Jauh (1000 kVA) terindikasi mendekati batas overload dimana untuk pengaturan alert pada transformator sebesar $50 \%$, sedangkan beban operasi sebesar $493 \mathrm{kVA}$ yaitu 49\% dari kapasitas trafo. Hal tersebut terjadi saat pompa transfer SP-04 dan SP-05.

Adapun rincian hasil evaluasi gangguan critical sebagai berikut :

1. Untuk Trafo KW-03 2, pembebanan trafo masih di bawah batas pembebanan yang ditetapkan oleh PT. PLN yaitu $80 \%$ pembebanan ideal, maka hal tersebut ditindaklanjuti dengan mengubah pengaturan alert pada $65 \%$ atau 130 KVA.

2. Untuk Trafo KW-03 3, pembebanan trafo masih di bawah batas 
pembebanan yang ditetapkan oleh PT. PLN yaitu $80 \%$ pembebanan ideal), maka hal tersebut ditindaklanjuti dengan mengubah pengaturan alert pada $65 \%$ atau $130 \mathrm{KVA}$.

3. Untuk Trafo SP-05 2, trafo tersebut merupakan trafo yang diparalel dengan Trafo SP-05 1, namun berbeda pengaturan tapping pada masing-masing trafo mengakibatkan perbedaan nilai impedansi dan tegangan impedansi sehingga beban tidak seimbang dan menyebabkan salah satu trafo mengalami overload. Solusinya dengan mengubah tapping untuk kedua trafo menjadi skala 5 .

4. Untuk Trafo Timur Jauh, pembebanan trafo masih di bawah batas pembebanan yang ditetapkan oleh PT. PLN yaitu $80 \%$ pembebanan ideal, maka hal tersebut ditindaklanjuti dengan mengubah pengaturan alert pada $65 \%$ atau $650 \mathrm{KVA}$.

Adapun rincian hasil evaluasi gangguan marginal sebagai berikut :

1. Untuk Bus Gudang Handak dan Bus KW-36T terindikasi terjadi over voltage dimana masih disuplai oleh Trafo KW-37, oleh karena itu solusi yang dilakukan dengan menurunkan tapping hingga ke nominal tegangan yang ideal $+/-5 \%$ dari $380 \mathrm{~V}$ dari tap 5 menjadi 3.

2. Untuk Bus KW-03, Bus KW-06, Bus KW-22T, Bus KWP-01 dan Bus SP02 terindikasi terjadi over voltage dimana masih disuplai oleh Trafo KW-03 2 dan Trafo KW-03 3, oleh karena itu solusi yang dilakukan dengan menurunkan tapping hingga ke nominal tegangan yang ideal $+/$ 5\% dari 380V dari tap 5 menjadi 4.

3. Untuk Bus SP-01 terindikasi terjadi over voltage dimana masih disuplai oleh Trafo KW-08 2, oleh karena itu solusi yang dilakukan dengan menurunkan tapping hingga ke nominal tegangan yang ideal $+/-5 \%$ dari $380 \mathrm{~V}$ dari tap 5 menjadi 3.

4. Untuk Bus KW-08, Bus KW-13 dan Bus KW-17 terindikasi terjadi over voltage dimana masih disuplai oleh Trafo KW-08 1, oleh karena itu solusi yang dilakukan dengan menurunkan tapping hingga ke nominal tegangan yang ideal $+/-5 \%$ dari $380 \mathrm{~V}$ dari tap 5 menjadi 4.

5. Untuk Bus SP-04 terindikasi terjadi over voltage dimana masih disuplai oleh Trafo SP-04 2, oleh karena itu solusi yang dilakukan dengan menurunkan tapping hingga ke nominal tegangan yang ideal $+/-5 \%$ dari $380 \mathrm{~V}$ dari tap 5 menjadi 3.

6. Untuk Bus SP-SS 03 terindikasi terjadi over voltage dimana masih disuplai oleh Trafo SP-SS, oleh karena itu solusi yang dilakukan dengan menurunkan tapping hingga ke nominal tegangan yang ideal $+/$ $5 \%$ dari $380 \mathrm{~V}$ dari tap 5 menjadi 3 .

7. Untuk Trafo SP-05 1, pembebanan trafo masih di bawah batas pembebanan yang ditetapkan oleh PT. PLN yaitu $80 \%$ pembebanan ideal maka hal tersebut ditindaklanjuti dengan mengubah pengaturan alert pada $65 \%$ atau $130 \mathrm{KVA}$.

8. Untuk Trafo Timur Jauh, pembebanan trafo masih di bawah batas pembebanan yang ditetapkan oleh PT. PLN yaitu $80 \%$ pembebanan ideal maka hal tersebut ditindaklanjuti dengan mengubah pengaturan alert pada $65 \%$ atau $650 \mathrm{KVA}$.

9. Untuk Bus KW-77 dan Bus KW-84, terjadi under voltage yang disebabkan ketidakseimbangan pada hubungan paralel Trafo SP-05 1 dan Trafo SP052 , setelah penyesuaian tapping 
(tap 5) tegangan kembali ke nominal tegangan yang ideal $+/-5 \%$ dari $380 \mathrm{~V}$.

10. Untuk Bus Kantor Desa, Bus KW-71, Bus KWP-20, Bus Picis, Bus Sarana Umum masih dalam satu SDP yaitu SDP Gunung Picis dimana secara simulasi tegangan input sudah turun menjadi $361 \mathrm{~V}$, hal ini disebabkan karena jarak SDP dari Pembangkit sejauh 720 meter.

11. Untuk itu perlu dinaikan tegangan dengan pengadaan transformator step up $380 \mathrm{~V}$ to $400 / 440 / 460 \mathrm{~V}$ dengan kapasitas $125 \mathrm{kVA}$.

\subsection{Pengembangan dan Keekonomian}

Rencana penyambungan jalur PLN $20 \mathrm{kV}$ dengan kapasitas kebutuhan daya sebesar $1450 \mathrm{kVA}$ yang akan menggantikan Generator D3512B2 dengan kapasitas 1500 kVA. Berdasarkan hasil simulasi tidak ditemukan gangguan baik pada tegangan kabel, bus ataupun perangkat listrik lainnya. Hal ini dapat dimungkinkan apabila hasil temuan sebelumnya sudah dilakukan.

Untuk aspek keekonomian pada penelitian ini yaitu dengan menghitung nilai penghematan dan waktu pengembalian modal atau Pay Back Period (PBP). Untuk itu harus diketahui nilai investasi awal yang ditunjukkan pada tabel 2 berikut ini :

Tabel 2. Biaya Investasi Awal

\begin{tabular}{|l|r|}
\hline \multicolumn{1}{|c|}{ Investasi } & Harga (Rp) \\
\hline Biaya Penyambungan Baru & $914.950 .000,-$ \\
\hline Uang Jaminan Langganan & $326.250 .000,-$ \\
\hline Sertifikat Laik Operasi & $20.000 .000,-$ \\
\hline
\end{tabular}

\begin{tabular}{|l|r|}
\hline $\begin{array}{l}\text { Transformator 1.8 MVA, } \\
20 / 0.4 \mathrm{kV}\end{array}$ & $290.000 .000,-$ \\
\hline Cubicle $20 \mathrm{kV}, 720 \mathrm{~A}$ & $150.000 .000,-$ \\
\hline $\begin{array}{l}\text { Pembuatan Gardu Trafo \& } \\
\text { Instalasi }\end{array}$ & $487.000 .000,-$ \\
\hline Total Investasi & $2.188 .200 .000,-$ \\
\hline
\end{tabular}

Dari hasil perhitungan biaya investasi dapat diketahui nilai penghematan dari rencana pengembangan ini. Dalam penelitian ini digunakan sampling data selama satu bulan yaitu pada bulan Maret 2019. Adapun parameter untuk mengetahui persentase penghematan dapat dilihat pada tabel 3 berikut ini :

Tabel 3. Persentase Hasil Penghematan

\begin{tabular}{|l|r|}
\hline \multicolumn{1}{|c|}{$\begin{array}{c}\text { Konsumsi Energi dan } \\
\text { Biaya }\end{array}$} & Harga (Rp) \\
\hline \hline Konsumsi Energi rata-rata & $914.950 .000,-$ \\
\hline Konsumsi Energi Reaktif & $326.250 .000,-$ \\
\hline Konsumsi Solar rata-rata & $20.000 .000,-$ \\
\hline Biaya Solar & $290.000 .000,-$ \\
\hline Tarif untuk Rp./kWh LWBP & $150.000 .000,-$ \\
\hline Tarif untuk Rp./kWh WBP & $487.000 .000,-$ \\
\hline Tarif untuk Rp./kVARh & $2.188 .200 .000,-$ \\
\hline $\begin{array}{l}\text { Total Biaya PLN } \\
\text { (kWh+kVARh) }\end{array}$ & $28.075 .287,-$ \\
\hline Biaya PM250 dan PM2000 & $1.728 .000,-$ \\
\hline Biaya Pembangkitan Genset & $2.544,-$ \\
\hline $\begin{array}{l}\text { Biaya Pembangkita } \\
\text { (kWh+kVARh) }\end{array}$ & $1.279,-$ \\
\hline $\begin{array}{l}\text { Penghematan Pemakaian } \\
\text { Listrik }\end{array}$ & $50 \%$ \\
\hline
\end{tabular}


Setelah memperoleh perhitungan biaya investasi serta potensi penghematan yang dapat diperoleh. Perlu kita ketahui nilai Pay Back Period (PBP) dari proyek ini dengan membandingkan pemakaian energi, biaya pembangkitan genset, biaya pembangkitan PLN selama kurun waktu satu tahun. Untuk perhitungan dapat dilihat pada Tabel 4 .

Tabel 4. Perhitungan Pay Back Period

\begin{tabular}{|l|r|}
\hline \multicolumn{1}{|c|}{$\begin{array}{c}\text { Konsumsi Energi dan } \\
\text { Biaya }\end{array}$} & Harga (Rp) \\
\hline \hline Pemakaian Energi 1 tahun & $8.011 .750,-$ \\
\hline $\begin{array}{l}\text { Biaya Pembangkitan } \\
\text { Genset 1 tahun }\end{array}$ & $20.389 .036 .247,-$ \\
\hline $\begin{array}{l}\text { Biaya Pembangkitan PLN } \\
\text { 1 tahun }\end{array}$ & $10.247 .479 .937,-$ \\
\hline Penghematan 1 tahun & $10.141 .556 .309,-$ \\
\hline Pay Back Periode (PBP) & 2.59 Bulan \\
\hline
\end{tabular}

\section{KESIMPULAN}

Berdasarkan beberapa analisis yang telah dilakukan untuk melakukan kajian simulasi aliran beban pada sistem tenaga listrik di PT $\mathrm{XYZ}$, maka diperoleh kesimpulan sebagai berikut:

1. Dari hasil simulasi dapat disimpulkan terdapat 3 unit trafo (KW-03 2, KW-03 3 dan Timur Jauh) mengalami overload melebihi 50\% dari kapasitas trafo, beberapa bus load mengalami over voltage diakibatkan pengaturan tapping trafo yang tidak sesuai dan pada SDP Gunung Picis mengalami under voltage diakibatkan beban dan jarak kabel sehingga mengakibatkan tegangan jatuh dapat ditindaklanjuti dengan pemasangan transformator $125 \mathrm{kVA}$ yang sesuai. Gangguan overload terbesar terjadi pada trafo SP-05 yang mencapai 96\%, hampir mendekati kapasitas maksimum trafo, hal ini disebabkan pengaturan tapping yang berbeda disaat trafo dihubung parallel.

2. Dari hasil simulasi dapat disimpulkan terkait rencana penyambungan jalur PLN $20 \mathrm{kV}$ sudah layak untuk dilakukan, dikarenakan tidak ada temuan potensi gangguan selama sumber PLN $20 \mathrm{kV}$ dioperasikan.

3. Secara keekonomian dari biaya investasi yang digunakan apabila dibandingkan dengan biaya operasional perusahaan dapat menghemat sebesar 50\% setiap hari operasi dan untuk nilai Pay Back Period dapat terpenuhi dalam 78 hari.

\section{DAFTAR PUSTAKA}

Efendi, Juri. 2018. "Analisis Aliran Beban Pada Sistem Tenaga Listrik Menggunakan Software ETAP 12.6". Universitas Muhammadiyah Surakarta.

Hadi Saadat, 1999 , "Power System Analysis" McGraw-Hill, Singapore

Kumulo,Cahyo. 2018. "Analisis Aliran Beban Pada Sistem Tenaga Listrik Di KSO XYZ Menggunakan Software ETAP 12.6", PT. Prolindo Aditya Prima Surabaya. Surabaya.

Marsudi, Djiteng, Ir. 2005. "Pembangkitan Energi Listrik", Erlangga. Jakarta.

Prasudyana, ST. "Electric Protection", Pusdiklat Migas. Cepu.

SJ. Masykur. Ir. MT.2016. "Analisis Sistem Tenaga Listrik", USU Press. Medan.

Zuhal.1982.’Dasar Tenaga Listrik", Penerbit ITB. Bandung. 